\title{
Inactivation of the infralimbic but not the prelimbic cortex impairs consolidation and retrieval of fear extinction
}

\author{
Vincent Laurent and R. Frederick Westbrook ${ }^{1}$ \\ School of Psychology, The University of New South Wales, Sydney, New South Wales 2052, Australia
}

\begin{abstract}
Rats were subjected to one or two cycles of context fear conditioning and extinction to study the roles of the prelimbic cortex (PL) and infralimbic cortex (IL) in learning and relearning to inhibit fear responses. Inactivation of the PL depressed fear responses across the first or second extinction but did not impair learning or relearning fear inhibition (experiment 1). Inactivation of the IL did not affect inhibition across the first extinction but disrupted its long-term retention. Inactivation of the IL impaired inhibition across the second extinction, and inactivation before or after this extinction impaired long-term retention (experiments 2 and 3). Inactivation of the IL before the retention test restored extinguished fear responses (experiment 4). These results show for the first time that neuronal activity in the PL is involved in the expression of fear responses but not in the learning that underlies long-term fear inhibition. They also confirm that the IL is involved in this inhibitory learning: Specifically, they show that the IL is critical for consolidation and retrieval of this inhibitory learning. The role of the IL is discussed in terms of a contemporary neural model of fear extinction.
\end{abstract}

Experimental extinction is widely used to study the neural substrates underlying the inhibition of Pavlovian conditioned fear responses. Extinction occurs when the signaling relation between a conditioned stimulus (CS) and an aversive unconditioned stimulus (US) is broken by repeated exposures to the CS in the absence of the US. The fear responses (e.g., freezing, potentiated startle) produced by the signaling relation decline across the CS alone exposures and eventually cease to occur. Fear of the CS is said to be extinguished. A historically important explanation of extinction was that breaking the relation between the CS and US weakened and eventually erased the association formed by that relation (Rescorla and Wagner 1972). However, it is now clear that this explanation is at best incomplete. Various phenomena show that retraining the CS-US association is not necessary for the restoration of fear responses to an extinguished CS (Bouton et al. 2006). These phenomena include the "renewal" of fear responses when the CS is tested outside the context where extinction had occurred, the "spontaneous recovery" of such responses with the elapse of time since extinction, and the "reinstatement" of fear responses when the extinguished CS is tested in the presence of or shortly after exposure to danger. Such restoration phenomena show that at least some of the original association survives extinction in spite of the fact that the CS fails to elicit fear responding. This implies that extinction involves new learning which coexists with the old while inhibiting its expression in fear responses (Myers and Davis 2007; Quirk and Mueller 2008).

A wealth of evidence indicates that this inhibitory learning involves interactions between the basolateral amygdala (BLA) and the medial prefrontal cortex (mPFC). The BLA contributes to both acquisition and consolidation of inhibition: Acquisition requires activation of $\mathrm{N}$-methyl-D-aspartate receptors (NMDAr), metabotropic glutamate receptors, or mitogen-activated protein kinase (MAPk) (Herry et al. 2006; Kim et al. 2007; Sotres-Bayon et al. 2007, 2009; Laurent and Westbrook 2008; Laurent et al. 2008);

\footnotetext{
'Corresponding author.
}

E-mail f.westbrook@unsw.edu.au; fax 61-92-03853044.

Article is online at http://www.learnmem.org/cgi/doi/10.1101//m.1474609. consolidation does not involve NMDAr activation but does require neuronal activity and protein synthesis (Lin et al. 2003; Laurent et al. 2008). In contrast, the mPFC does not appear to be necessary for the acquisition of inhibition but is required for its consolidation (Santini et al. 2004; Hugues et al. 2006; Sierra-Mercado et al. 2006; Burgos-Robles et al. 2007; Laurent and Westbrook 2008; Sotres-Bayon et al. 2009): For example, local blockade of NMDAr does not impair the inhibition of fear responses across extinction but does impair the retention of this inhibition, showing that it disrupts the consolidation required for long-term fear inhibition. Moreover, electrophysiological studies have revealed that neurons in the mPFC, specifically in the infralimbic region (IL), increased firing across presentations of an already extinguished CS implying that these neurons are involved in the retrieval of extinction (Herry and Garcia 2002; Milad and Quirk 2002). Such evidence has led to the view that the mPFC controls the activation of inhibitory mechanisms in the amygdala that suppress fear responding following extinction (Quirk and Mueller 2008).

This view has received support from recent studies of the neural mechanisms underlying relearning to inhibit fear responses (Kim and Richardson 2008; Laurent and Westbrook 2008; Laurent et al. 2008; Hart et al. 2009). Relearning occurs when an extinguished CS is paired with the aversive US and the fear responses produced by that retraining are again extinguished. Similar to acquisition of inhibition in initial extinction, activation of NMDAr in the BLA is critical for acquisition of this inhibition across the second extinction, and their activation in the mPFC remains critical for its consolidation (Laurent and Westbrook 2008). However, in contrast to initial acquisition, reacquisition of inhibition also requires NMDAr activation in the mPFC and consolidation does not require neuronal activity in the BLA. Moreover, and surprisingly, relearning to inhibit fear responses can occur and is even facilitated in the absence of neuronal activity in the BLA. These findings suggest that activity in amygdala-based fear circuits requires NMDAr in the BLA for learning inhibition of this fear: Blockade of NMDAr containing the NR2B subunit or depression of neuronal activity in the BLA impairs this learning. Activity in these circuits also requires 
NMDAr activation to relearn inhibition of the fear produced by retraining, but depression of these amygdala-based fear circuits allows other structures, notably the mPFC and most likely the IL, to compensate and support relearning of inhibition.

The mPFC therefore appears to control the activation of inhibitory mechanisms when neuronal activity in the BLA is disrupted across second extinction. If so, inhibition of fear responses across this training should be impaired by mPFC inactivation. However, previous investigations failed to find such impairment (Laurent and Westbrook 2008). The mPFC is a cortical structure composed of several nuclei, including the IL and the prelimbic cortex (PL). Both nuclei exert an influence over fear responding, but they do so in a specific and opposite manner. For instance, stimulation of neurons in the PL increases, whereas stimulation of neurons in the IL decreases, conditioned fear responses (Vidal-Gonzalez et al. 2006). As noted previously, electrophysiological studies have shown that neurons in the IL subregion of the mPFC increased firing across presentation of an already extinguished CS, implying that these neurons are involved in learned inhibition of fear responses (Milad and Quirk 2002). Thus, the PL appears to play a role in the expression of fear responses, whereas the IL may be a site at which the inhibition acquired across extinction is stored and whose subsequent retrieval activates fear inhibitory mechanisms in the amygdala. If correct, these suggestions imply that selective inactivation of the IL, but not of the PL, will impair inhibition of fear responses across second extinction training.

The present experiments study the role of these nuclei in learning and relearning to inhibit fear in extinction. The first two experiments involved subjecting rats to a single cycle of conditioning and extinction or two such cycles. In experiment 1 , rats were infused in the PL with either vehicle or muscimol, a GABA agonist that disrupts neuronal activity, prior to either their first and only extinction or their second extinction. Experiment 2 was identical to experiment 1 except that infusions occurred in the IL. Previous findings indicate that the IL, but not the PL, is involved in inhibiting conditioned fear responses. Therefore, inactivation of IL should impair, whereas inactivation of the PL should spare, learning and relearning to inhibit fear responses in extinction. The next two experiments provided a further study of the role played by the IL in fear inhibition. In experiment 3 , rats were subjected to two cycles of conditioning and extinction. Muscimol or vehicle was infused in the IL immediately after the second extinction. If the IL contributes to consolidation of the inhibition produced by the second extinction, then muscimol should impair retention of that inhibition when assessed the following day. Finally, experiment 4 subjected rats to a single cycle of conditioning and extinction. A retention test was conducted the following day under IL infusion of either vehicle or muscimol. As suggested by electrophysiological findings, inactivation of the IL prior to test should impair the retrieval and/or expression of the inhibition produced by extinction.

\section{Results}

\section{Experiment 1: Inactivation of the PL spares learning and relearning inhibition}

The PL is involved in the expression of learned fear. As noted, stimulation of PL neurons increases, whereas inactivation of these neurons decreases, conditioned fear responses (Vidal-Gonzalez et al. 2006; Corcoran and Quirk 2007). However, it remains unclear as to whether the PL contributes to learned inhibition produced by extinction. Experiment 1 therefore examined the effects of selective inactivation of the PL on learning and/or relearning to inhibit fear responses. Rats were bilaterally im- planted with cannulas targeting the PL and were randomly assigned to one of the two experimental conditions (see Fig. 2A). Rats in groups Re-extinction were submitted to context fear conditioning on days 1 and 3 and to extinction on days 2 and 4 . The re-extinction session on day 4 was performed under PL infusion of either muscimol (group Re-extinction-Muscimol) or saline (group Re-extinction-Vehicle). Rats in groups Extinction received the same procedure except that the initial extinction session on day 2 was omitted: They received their first extinction on day 4. Long-term extinction and re-extinction were assessed in all rats across a retention test given on day 5 .

\section{Histology}

Figure 1A shows the location of injection cannula tips. A total of 16 rats were excluded because of incorrect placement. This yielded the following group sizes: group Extinction-Vehicle $(n=8)$, group Extinction-Muscimol $(n=8)$, group Re-extinction-Vehicle $(n=6)$, and group Re-extinction-Muscimol $(n=8)$.

\section{Behavior}

Levels of freezing to the context across extinction, re-extinction, and test are shown in Figure 2. Context conditioning on day 1 was successful, as rats returned to the context on day 2 for initial extinction displayed substantial freezing (groups Re-extinction; Fig. 2B). Freezing decreased across the extinction session $\left(F_{(1,12)}=\right.$ 95.5, $P<0.05)$. This decrease was retained, since on day 3 rats that had undergone extinction froze significantly less than the other rats during the period prior to shock (groups Extinction; $F_{(1,26)}=$ 23.7, $P<0.05$; data not shown). The shock restored extinguished fear responses. When returned to the context on day 4 (Fig. 2C), vehicle-treated rats showed substantial and similar levels of freezing whether they had or had not undergone extinction (group Re-extinction-Vehicle vs. group Extinction-Vehicle; $\left.F_{(1,26)}=2.4, P>0.05\right)$. Muscimol infused into the PL depressed fear responses. Rats infused with muscimol froze significantly less than rats infused with saline $\left(F_{(1,26)}=40.4, P<0.05\right)$. Although all muscimol-treated rats showed comparably low levels of freezing $\left(F_{(1,26)}=0.1, P>0.05\right)$, there was a significant linear trend, showing that freezing declined across the session $\left(F_{(1,26)}=145.4, P<0.05\right)$.

The test data on day 5 (Fig. 2D) showed that neuronal activity in the PL is not necessary for learning and relearning extinction of context conditioned fear. Rats that had been infused with muscimol froze just as little as their respective controls $\left(F_{(1,26)}=0.4, P>\right.$ 0.05 for groups Extinction; $F_{(1,26)}=0.0, P>0.05$ for groups Reextinction), and these low levels of freezing were similar to those shown at the end of extinction or re-extinction on the previous day. There was no significant difference between muscimoltreated rats $\left(F_{(1,26)}=1, P>0.05\right)$ or between saline-treated rats $\left(F_{(1,26)}=0.2, P>0.05\right)$.

\section{Experiment 2: Inactivation of the IL impairs learning and relearning extinction}

Disrupting neuronal activity in the mPFC impairs learning and relearning to inhibit fear responses in extinction (Sierra-Mercado et al. 2006; Laurent and Westbrook 2008). Experiment 1 showed that this impairment is not due to a disruption of activity in the PL. This finding is consistent with in vivo electrophysiological studies providing evidence of a role for the IL in the inhibition of fear responses in extinction (Herry and Garcia 2002; Milad and Quirk 2002). The present experiment therefore examined whether selective inactivation of the IL impairs the inhibitory learning produced by initial or second extinction. It used the same design as in the previous experiment (Fig. 3A) except that infusions occurred in the IL. Therefore, rats were infused in the IL with either muscimol (groups Extinction-Muscimol and 
A

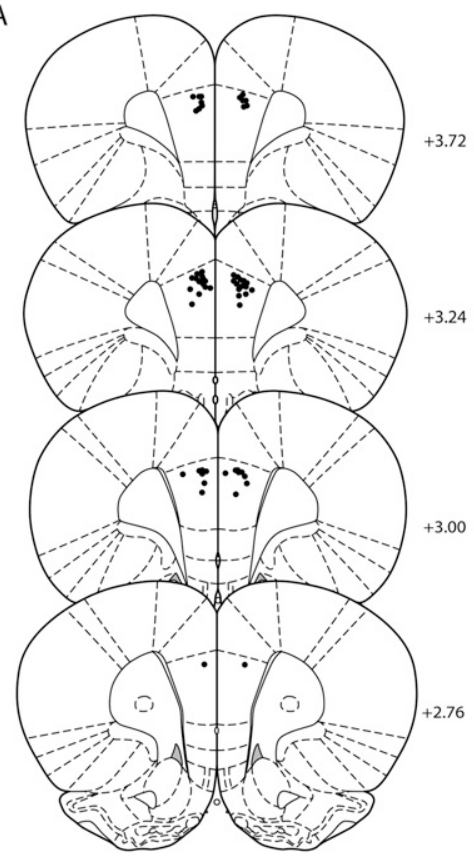

C

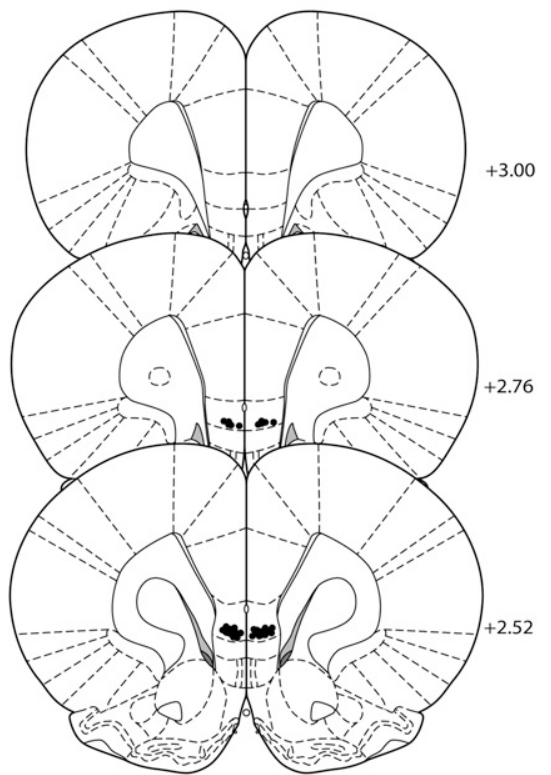

B

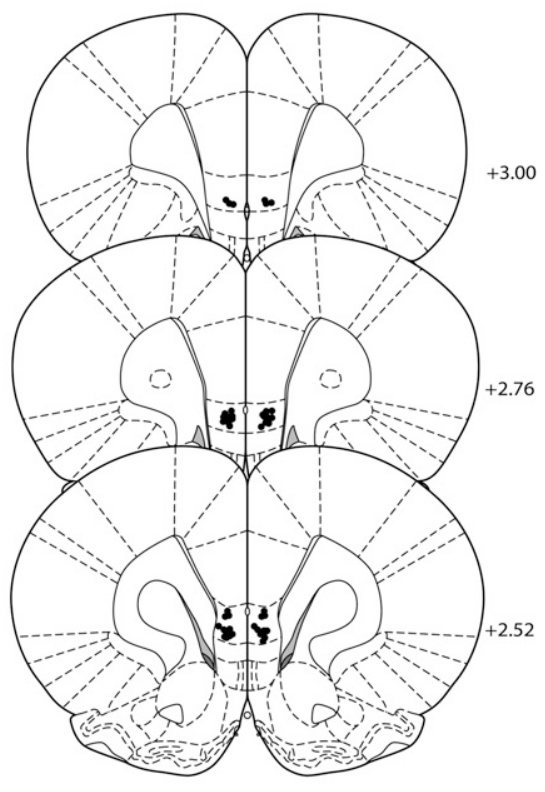

D

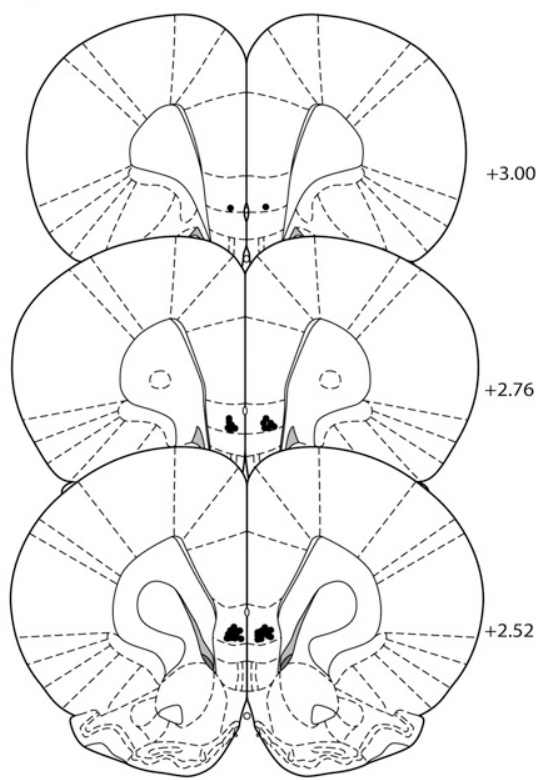

Figure 1. Location of microinjection cannulas within the $\mathrm{IL}$ or the $\mathrm{PL}$ for all rats included in the final analysis of experiments $1(A), 2(B), 3(C)$, and $4(D)$. Distances on the atlas templates (adapted from Paxinos and Watson 2007 and reprinted here with permission from Elsevier (C2007) are indicated in millimeters from bregma.

Re-extinction-Muscimol) or saline (groups Extinction-Vehicle and Re-extinction-Vehicle) before being submitted to their first or second extinction on day 4 .

\section{Histology}

Figure $2 \mathrm{~B}$ shows the location of injection cannula tips. A total of seven rats were excluded because of incorrect placements. This yielded the following group sizes: group Extinction-Vehicle $(n=6)$, group Extinction-Muscimol $(n=7)$, group Re-extinctionVehicle $(n=6)$, and group Re-extinction-Muscimol $(n=6)$.

\section{Behavior}

Levels of freezing to the context across extinction, re-extinction, and test are shown in Figure 3 . The conditioning episode on day 1 was successful. Rats in groups Re-extinction exhibited substantial levels of freezing when returned to the context for extinction on day 2 (Fig. 3B). These levels significantly declined over the course of the session $\left(F_{(1,10)}=\right.$ 102.7, $P<0.05)$. On day 3 , these rats showed long-term retention of extinction (data not shown). They froze significantly less before the shock than rats that had not yet received any extinction (groups Extinction; $F_{(1,21)}=34.4, P<$ 0.05). This shock restored extinguished fear responses. Rats in groups ExtinctionVehicle and Re-extinction-Vehicle showed substantial and similar levels of freezing during exposure to the context for extinction or re-extinction on day 4 $\left(F_{(1,21)}=0.1, P>0.05\right.$; Fig. 3C). IL infusion of muscimol spared the short-term inhibition of fear responses across extinction, but impaired this inhibition across re-extinction. Rats in group ExtinctionMuscimol froze just as much as did rats infused with saline (groups ExtinctionVehicle and Re-extinction-Vehicle; $\left.F_{(1,21)}=0.1, P>0.05\right)$. In contrast, rats in group Re-extinction-Muscimol froze significantly more than saline-treated rats $\left(F_{(1,21)}=12.2, P<0.05\right)$. In addition, rats in group Extinction-Muscimol froze significantly less than rats in group Reextinction-Muscimol $\left(F_{(1,21)}=8.7, P<\right.$ $0.05)$. Overall, levels of freezing significantly decreased across the session $\left(F_{(1,21)}=133.2, P<0.05\right)$.

The retention test data (Fig. 3C) revealed that IL infusion of muscimol impaired long-term retention of the inhibition produced by both initial and second extinction. Rats in group ExtinctionMuscimol exhibited more responses across test than rats in group ExtinctionVehicle $\left(F_{(1,21)}=21.4, P<0.05\right)$. A similar outcome was obtained when muscimol was infused prior to re-extinction training $\left(F_{(1,21)}=22.1, P<0.05\right)$. Vehicletreated rats (groups Extinction-Vehicle and Re-extinction-Vehicle) displayed similar levels of freezing whether they had received one or two extinction sessions $\left(F_{(1,21)}=0.5, P>0.05\right)$. Similarly, there was no difference between rats that had been infused with muscimol (groups Extinction-Muscimol and Re-extinction-Muscimol; $F_{(1,21)}=0.2$, $P>0.05)$.

\section{Experiment 3: Inactivation of the IL impairs the consolidation of re-extinction}

Experiment 2 showed that IL infusion of muscimol spared shortterm but impaired long-term inhibition of fear responses produced by the initial extinction. This suggests that neuronal activity in the 
A

\begin{tabular}{cccccc} 
Groups & Day 1 & Day 2 & Day 3 & Day 4 & Day 5 \\
\hline Extinction & + & & + & $4-$ & - \\
Re-extinction & + & - & + & $4-$ & -
\end{tabular}

the second extinction (Fig. 4A). Rats were trained to fear a context on day 1 and submitted to an extinction session on day 2. They were retrained to fear the context on day 3 and submitted to a reextinction session on day 4 . Immediately after this session, rats were infused in the IL with either muscimol (group Reextinction-Muscimol) or saline (group Re-extinction-Vehicle). A control group was included in order to assess the effectiveness of the second extinction in producing long-term fear inhibition. This group was treated in the same way as the other groups and received IL infusion of muscimol on day 4 but without the reextinction session. Levels of conditioned fear responses were assessed on day 5 .

\section{Histology}

Figure 1C shows the approximate location of injection cannula tips. A total of nine rats were excluded because of incorrect placement. This yielded the following group sizes: group Re-extinctionVehicle $(n=7)$, group Re-extinctionMuscimol $(n=7)$, and group Control Re-extinction $(n=7)$.

\section{Behavior}

Levels of freezing to the context across extinction, re-extinction, and test are shown in Figure 4 . The conditioning episode given on day 1 was successful. All rats showed substantial levels of freezing when returned to the chambers for the first extinction session on day 2 (Fig. 4B). These levels gradually and significantly declined over the course of the session $\left(F_{(1,18)}=106.1, P<0.05\right)$. Extinguished fear responses were restored by the reconditioning episode given on day 3 . When returned to the context on day 4 , rats in groups Re-extinction exhibited substantial levels of fear responses (Fig. 4C), and these levels declined across the reextinction session $\left(F_{(1,12)}=889.5, P<0.05\right)$.

The test data on day 5 (Fig. 4D)

Figure 2. Inactivation of the PL spares learning and relearning extinction. $(A)$ Description of the behavioral procedures used in experiment $1(+$, shocked exposure to the chambers; - , nonshocked exposure to the chambers). (B) All illustrations show the mean and SEM levels of freezing. All rats lost freezing responses across the initial extinction performed drug-free (Groups Re-extinction). (C) Rats infused with vehicle before their first (Group Extinction-Vehicle) or their second (Group Re-extinctionVehicle) extinction lost freezing responses across the session. PL infusion of muscimol reduces fear responses in both extinction and re-extinction (Groups Extinction-Muscimol and Re-extinctionMuscimol). (D) The retention test showed that inactivation of the PL spares learning and relearning extinction.

showed that neuronal activity in the $\mathrm{IL}$ is required for consolidation of reextinction memory. Rats in group Reextinction-Muscimol froze significantly more than rats in group Re-extinctionVehicle $\left(F_{(1,17)}=10.1, P<0.05\right)$ and just as much as control rats not subjected to that second extinction $\left(F_{(1,17)}=0.1, P>\right.$

0.05). The infusion of muscimol by itself

IL is not required for learning to inhibit fear responses across extinction but is required for the consolidation of this inhibition (Burgos-Robles et al. 2007; Laurent and Westbrook 2008). That experiment also showed that IL infusion of muscimol impaired both short- and long-term inhibition of fear responses produced by the second extinction. This suggests that neuronal activity in the IL is required both to relearn inhibition and to consolidate this inhibition. Experiment 3 investigated the role of the IL in consolidating the relearned inhibition by infusing muscimol after was without effect since rats in group Control Re-extinction showed equivalent levels of freezing whether they were infused in the IL with either saline or muscimol $\left(F_{(1,12)}=3.0, P>0.05\right)$.

\section{Experiment 4: Inactivation of the IL impairs retrieval of learned inhibition}

Neuronal activity in the basolateral complex of the amygdala is necessary for learning but not relearning to inhibit fear responses 
A

\begin{tabular}{cccccc} 
Groups & Day 1 & Day 2 & Day 3 & Day 4 & Day 5 \\
\hline Extinction & + & + & $4-$ & - \\
Re-extinction & + & - & + & $4-$ & - \\
\hline T IL infusion of either Vehicle (saline) or Muscimol & $(6.25 \mathrm{ng} / \mu \mathrm{l} ; 0.2 \mu \mathrm{ll} \mathrm{per} \mathrm{side)}$ &
\end{tabular}

B

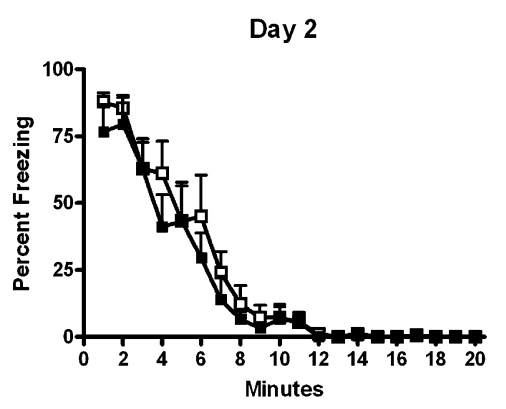

C

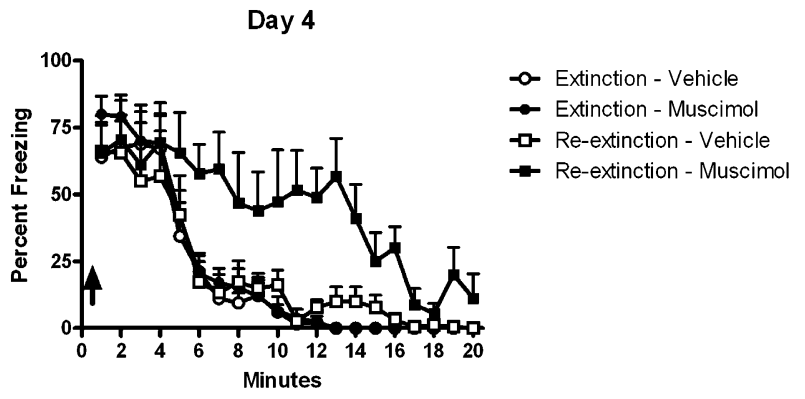

D

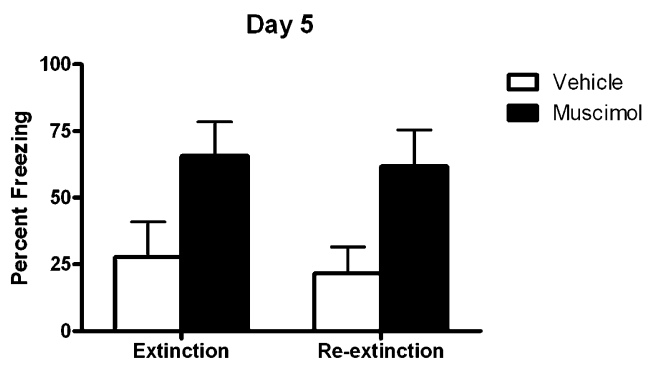

Figure 3. Inactivation of the IL impairs learning and relearning extinction. $(A)$ Description of the behavioral procedures used in experiment $2(+$, shocked exposure to the chambers; - , nonshocked exposure to the chambers). (B) All illustrations show the mean and SEM levels of freezing. (C) All rats lost freezing responses across the initial extinction performed drug-free (Groups Re-extinction). Rats infused with vehicle before their first (Group Extinction-Vehicle) or their second (Group Re-extinction-Vehicle) extinction lost freezing responses across the session. IL infusion of muscimol leaves intact the loss of freezing responses across initial extinction (Group Extinction-Muscimol). In contrast, the same infusion slows the loss of freezing responses across second extinction (Group Re-extinction-Muscimol). (D) The retention test showed that IL infusion of muscimol disrupts consolidation of extinction (Group Extinction-Muscimol). It also disrupted acquisition and perhaps consolidation of re-extinction (Group Re-extinction-Muscimol).

in extinction (Kim and Richardson 2008; Laurent and Westbrook 2008; Laurent et al. 2008). One explanation for this contrasting role is that the relearning produced by a second extinction involves activation and strengthening of circuitry in the mPFC established by the original learning. The results of experiment 2 suggest that this circuitry is located in the IL region of the MPFC since inactivation of the IL impaired both the development of inhibition across the second extinction and its long-term reten- tion. Effectively, that inactivation impaired activation of the original learning and the strengthening of this learning across the second extinction. The present experiment tested this explanation by examining whether reactivation of the learning produced by extinction does involve neuronal activity in the IL (Fig. 5A). Rats were submitted to context conditioning on days 1 and 3 and to a single extinction session on day 4 . They were tested for retention of extinction on day 5 under IL infusion of either muscimol (group Extinction-Muscimol) or saline (group Extinction-Vehicle). A control group was included to assess the effectiveness of extinction in promoting longterm learned inhibition. This group was treated in the same way except that they did not receive an extinction session on day 4 . This test also allows an assessment of the effects of muscimol in the IL in the absence of learned inhibition.

\section{Histology}

Figure 1D shows the approximate location of injection cannula tips. A total of seven rats were excluded because of incorrect placement. This yielded the following group sizes: group Extinction-Vehicle $(n=$ 7), group Extinction-Muscimol $(n=6)$, and group Control Extinction $(n=7)$.

\section{Behavior}

Levels of freezing to the conditioned context across extinction and test are shown in Figure 5. The two context conditioning episodes given on days 1 and 3 were successful. Rats in groups Extinction displayed substantial levels of freezing when returned to the chambers for extinction on day 4 (Fig. 5B). These levels significantly and gradually declined over the course of the session $\left(F_{(1,11)}=196.0, P<0.05\right)$.

The test data on day 5 (Fig. 5B) revealed that neuronal activity in the IL is necessary for the retrieval of the inhibitory memory established in extinction. Rats in group Extinction-Muscimol froze significantly more than rats in group Extinction-Vehicle $\left(F_{(1,16)}=38.0\right.$, $P<0.05)$, and the levels of freezing by rats in group Extinction-Muscimol were similar to rats in group Control Extinction $\left(F_{(1,16)}=0.2, P>0.05\right)$, showing that muscimol had restored inhibited fear responses. Moreover, there were no differences between control rats tested under saline or muscimol $\left(F_{(1,16)}=1.5, P>0.05\right)$, confirming that muscimol did not inflate fear responses.

\section{Discussion}

The present series of experiments subjected rats to two context conditioning episodes and a single extinction or two cycles of 
A

\begin{tabular}{cccccc}
\multicolumn{1}{c}{ Groups } & Day 1 & Day 2 & Day 3 & Day 4 & Day 5 \\
\hline Re-extinction & + & - & + & -4 & - \\
$\begin{array}{l}\text { Control } \\
\text { Re-extinction }\end{array}$ & + & - & + & 4 & -
\end{tabular}

4 IL infusion of either Vehicle (saline) or Muscimol $(6.25 \mathrm{ng} / \mu \mathrm{l} ; 0.2 \mu \mathrm{l}$ per side)

B

Day 2

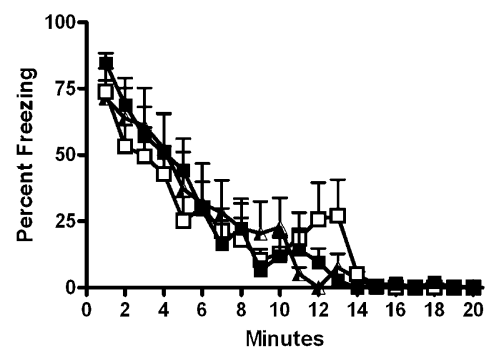

C

Day 4

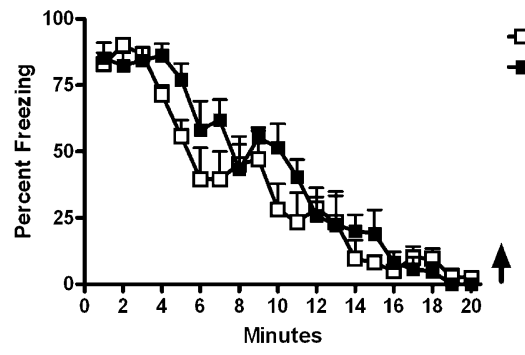

Day 5

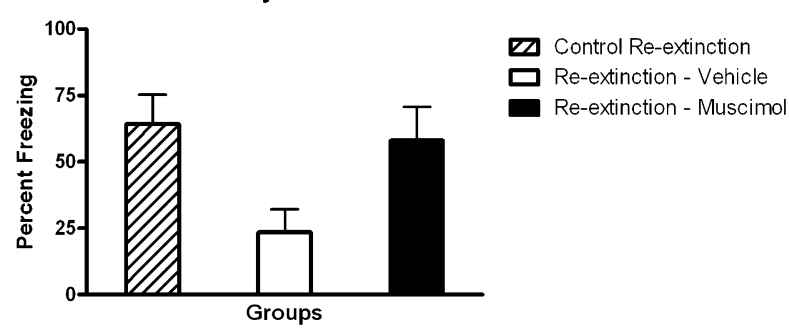

Figure 4. Inactivation of the IL impairs the consolidation of re-extinction. $(A)$ Description of the behavioral procedures used in experiment $3(+$, shocked exposure to the chambers; - , nonshocked exposure to the chambers). (B) All illustrations show the mean and SEM levels of freezing. All rats lost freezing responses across the initial extinction performed drug-free. (C) All rats lost freezing responses across the second extinction session performed drug-free. $(D)$ The retention test showed that muscimol impaired consolidation of re-extinction (Group Re-extinction-Muscimol).

context fear conditioning and extinction. The aim was to study the role played by the PL and IL in learning to inhibit fear responses across the initial extinction and relearning this inhibition across the second extinction. In experiment 1 , rats that received initial extinction under muscimol in the PL froze less across their first extinction than control rats but showed similar retention of learned inhibition when tested the following day. The same outcome was obtained when rats received their second extinction under muscimol in the PL: They exhibited less freezing than controls across that extinction but again showed similar levels of retention of inhibition on the subsequent drug-free test.
The depression of fear responses by infusion of muscimol into the PL is consistent with previous findings showing that stimulation of PL neurons increases, whereas their inactivation reduces, expression of conditioned fear responses (Vidal-Gonzalez et al. 2006; Corcoran and Quirk 2007). These findings confirm that the PL is involved in the expression of conditioned fear but does not contribute to learning or relearning to inhibit fear responses.

In experiment 2 , rats that received initial extinction under muscimol in the IL exhibited the same reduction in fear responses as did vehicle-treated rats but substantially more fear responses on the subsequent retention test. These results suggest that neuronal activity in the IL is not necessary for learning to inhibit fear responses across extinction but is required for its consolidation. This suggestion is consistent with previous findings showing that pharmacological manipulations involving the entire mPFC typically spare inhibition of fear responses in extinction but impair retention of this inhibition (Santini et al. 2004; Hugues et al. 2006; Burgos-Robles et al. 2007). They additionally show that the IL is the critical site within the mPFC for these effects. But the role of the IL changes from the initial to the second extinction. In experiment 2 , rats infused in the IL with muscimol before their second extinction took longer to inhibit fear responses across that session than did control rats. This result is consistent with the observation that IL neurons increase firing once extinction has been acquired and stored (Herry and Garcia 2002; Milad and Quirk 2002; Santini et al. 2008). Moreover, in experiment 2, muscimoltreated rats froze significantly more than vehicle-treated rats when subsequently tested drug-free. Thus, neuronal activity in the IL appears to be necessary for acquisition, and perhaps consolidation, of inhibition produced by second extinction. Taken together, these data suggest that neuronal activity in the IL is not required for acquisition of inhibition across extinction but is required for its consolidation. They also suggest that neuronal activity in the IL is required both for reacquisition of that inhibition and for its consolidation.

As just noted, experiment 2 demonstrated that neuronal activity in the IL is involved in relearning to inhibit fear responses: Rats that received their second extinction under an infusion of muscimol were impaired in developing inhibition across that session. Experiment 3 provided evidence that consolidation of this inhibition also requires the IL. Rats infused with muscimol immediately after their second extinction showed more fear responses on the subsequent retention test than did control rats infused with muscimol several hours after that second extinction, indicating that consolidation of inhibition had been disrupted by 
A

\begin{tabular}{lccccc}
\multicolumn{1}{c}{ Groups } & Day 1 & Day 2 & Day 3 & Day 4 & Day 5 \\
\hline Extinction & + & + & - & $4-$ \\
$\begin{array}{l}\text { Control } \\
\text { Extinction }\end{array}$ & + & + & & \\
T IL infusion of either Vehicle (saline) or Muscimol $(6.25 \mu \mathrm{g} / \mu \mathrm{l} ;$ & $0.2 \mu \mathrm{ll}$ per side $)$
\end{tabular}

B

Day 4

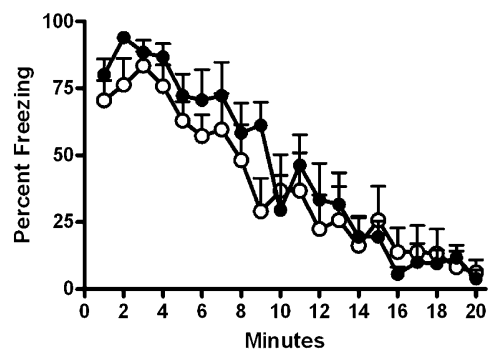

C

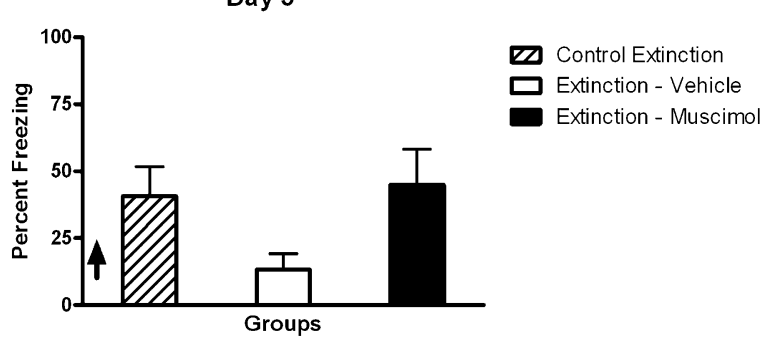

Figure 5. Inactivation of the IL impairs retrieval of learned inhibition. (A) Description of the behavioral procedures used in experiment $4(+$, shocked exposure to the chambers; - , nonshocked exposure to the chambers). (B) All illustrations show the mean and SEM levels of freezing. All rats lost freezing responses across the extinction session performed drug-free. (C) The retention test showed that muscimol restored freezing responses to the extinguished context (Group Extinction-Muscimol).

response (Sah et al. 2003). In addition to its key role in fear learning, the BLA is also necessary for acquisition and consolidation of extinction (Lin et al. 2003; Herry et al. 2006, 2008; Kim et al. 2007; Sotres-Bayon et al. 2007, 2009; Kim and Richardson 2008; Laurent and Westbrook 2008; Laurent et al. 2008; Hart et al. 2009). Recent evidence (Herry et al. 2008) has revealed that a distinct population of BLA neurons contributes to the inhibitory learning produced by extinction. These "extinction neurons" are selectively activated across CS-alone presentations, and their activation precedes the change from fear to fear suppression across extinction. This suppression is likely mediated by projections from the BLA to a network of inhibitory interneurons (intercalated cells [ITC], located between the BLA and the CeA) whose activation decreases activity of CeA fearoutput neurons (Royer et al. 1999; Royer and Pare 2002). Further, the pattern of activation of extinction neurons differs from that exhibited by another population of BLA neurons, "fear neurons," which only increased firing across CSUS pairings, suggesting that they are responsible for activation of CeA output neurons that mediates the fear response. These extinction and fear neurons also differ in term of anatomical organization such that extinction neurons are strongly and reciprocally connected to the mPFC. Thus, extinction neurons can transmit and receive the information from the $\mathrm{mPFC}$, which underlies long-term inhibition of conditioned fear responses following extinction.

In contrast to the BLA, activity in

the immediate infusion relative to the delayed infusion. Thus, neuronal activity in the IL is involved in consolidation of both learning (experiment 2) and relearning (experiment 3) to inhibit fear responses. Experiment 4 provided evidence that the IL is critical for retrieval and/or the expression of learned inhibition. In that experiment, rats that had learned to inhibit fear responses in extinction exhibited fear responses when tested under an infusion of muscimol relative to vehicle. This result is in agreement with electrophysiological studies showing that IL neurons increased firing in advance of the suppression of fear responses in extinction (Herry and Garcia 2002; Milad and Quirk 2002; Santini et al. 2008). Together, these results show that the IL is involved in retrieval and/or expression of the inhibition that suppresses fear responses after extinction.

The present findings can be viewed in terms of the contemporary model of fear inhibition shown in Figure 6 . This model holds that fear inhibition involves interactions among several brain regions, most notably, the BLA and the mPFC (Quirk and Mueller 2008). It is now widely accepted that information about the CS and the aversive US converges on neurons in the BLA to potentiate synaptic plasticity (Blair et al. 2001). This enables subsequent presentations of the CS to activate fear output neurons in the central nucleus of the amygdala (CeA). These neurons project to diencephalic and brainstem structures that control the behavioral, autonomic, and endocrine components of the fear the $\mathrm{mPFC}$ is not involved in the acquisition of extinction. However, activity in the mPFC is critical for consolidation of the inhibition produced by extinction (Santini et al. 2004; Hugues et al. 2006; Sierra-Mercado et al. 2006; Burgos-Robles et al. 2007; Laurent and Westbrook 2008; Sotres-Bayon et al. 2009). The current experiments confirm this view, but they additionally reveal that it is the activity in the IL subregion of the $\mathrm{mPFC}$ that is important for extinction (experiment 2). Moreover, muscimolinduced inactivation of the IL impaired the retrieval and/or expression of the inhibition produced by initial extinction (experiment 4). This latter finding is consistent with the hypothesis that the IL controls activation of inhibitory mechanisms in the amygdala to suppress fear responding to an extinguished CS (Quirk and Mueller 2008). This suppression is thought to occur through projections from the IL to the ITC (Pare and Smith 1993; McDonald 1998; Royer et al. 1999). For instance, stimulation of the IL decreases conditioned fear responses and the activity of CeA fear neurons that mediate these responses (Quirk et al. 2003; Vidal-Gonzalez et al. 2006). Further, retrieval and/or expression of the inhibition produced by extinction are impaired by lesions of ITC (Likhtik et al. 2008).

Relearning the inhibition produced by extinction also requires the BLA. For instance, blockade of NMDAr containing the NR2B subunit impairs the inhibition of fear responses across second extinction and the retention of that inhibition (Laurent 
A

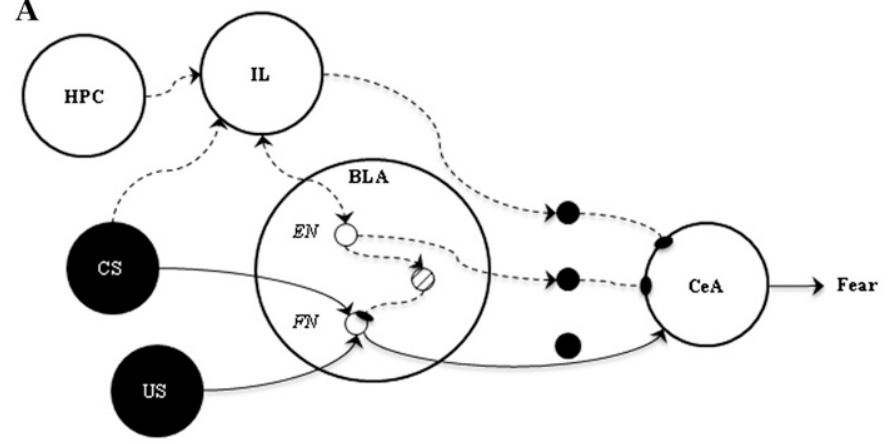

B

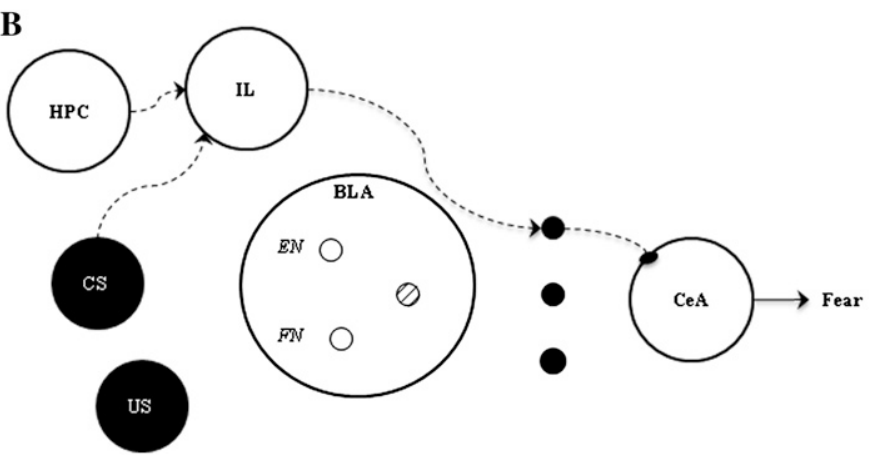

Figure 6. Neural circuit required for learning inhibition in either initial $(A)$ or second $(B)$ extinction.

\section{$\rightarrow$ Excitation \\ Inhibition \\ - Fear Pathway \\ -.. Inhibitory Pathway \\ Inhibitory Interneurons \\ Intercalated cells}

the ITC that suppress fear responding following second extinction.

Finally, it is worth noting that extinction of conditioned fear is an animal model for cue-exposure therapy that is used in the treatment of anxiety disorders such as posttraumatic stress disorder (PTSD). In cue exposure, the patient aided by the clinician confronts traumarelated cues in the absence of any advert danger. The aim of these confrontations is to reduce or inhibit the ability of the trauma-related cues to elicit the fear memories that are undermining the quality of the patient's life. The present experiments suggest that successful cue exposure requires proper functioning of the mPFC. Consistent with this view, studies in PTSD patients show lower activation in the mPFC when exposed to fearful stimuli (Bremner et al. 1999; Shin et al. 2001) concomitantly with higher activation of the amygdala. Thus, both animal and human studies converge on the view that interactions between the amygdala and the mPFC are critical for learned inhibition of fear and that dysfunctions in either sets of structures contribute to failures in this learned inhibition.

and Westbrook 2008). However, relearning occurs when both plasticity and neuronal activity in the BLA is disrupted across second extinction. A BLA infusion of muscimol or bupivicaine, a local anesthetic, depressed fear responses across second extinction but spared retention of the inhibition produced by that extinction (Kim and Richardson 2008; Laurent and Westbrook 2008). These findings are consistent with the model described. Behavioral studies have established that retraining an extinguished CS spares the inhibitory learning produced by extinction, as such a CS still exhibits the products of that learning, e.g., spontaneous recovery (Rescorla 2001; Leung and Westbrook 2008). This suggests that the inhibitory pathways established in initial extinction (see Fig. 6) survive retraining and are thus available for activation across second extinction. Experiment 1 confirmed this suggestion and showed that the IL is responsible for such inhibition: Local infusion of muscimol before second extinction retards the development of inhibition and impairs retention of that inhibition. Reactivation of the IL across presentation of an extinguished CS is in agreement with electrophysiological studies (Herry and Garcia 2002; Milad and Quirk 2002) as well as the results of experiment 4 . This experiment revealed that muscimol-induced inactivation of the IL restores extinguished fear responses on a retention test. Taken together, these findings suggest that disrupting neuronal activity in the BLA across second extinction engages compensatory mechanisms that are able to promote relearning of inhibition. The present experiments indicate that the IL, but not the PL, constitutes a component of the circuitry which underlies this compensation. Thus, we propose that exposure to a retrained CS across second extinction activates and strengthens via NMDAr-mediated changes the inhibitory circuits in the IL established by the initial extinction. This activation and strengthening can occur via an amygdala-independent pathway. Subsequent activation of this circuitry in the IL excites neurons in

\section{Materials and Methods}

\section{Subjects}

Subjects were 139 experimentally naïve male Wistar rats (Rattus norvegicus). They were obtained from a local supplier (Animal Resource Center, Canning Vale, Western Australia, Australia) and weighed between 250 and $350 \mathrm{~g}$. They were housed in plastic boxes $(22 \mathrm{~cm}$ high $\times 65 \mathrm{~cm}$ long $\times 40 \mathrm{~cm}$ wide $)$ located in a climate-controlled colony room under natural lighting. There were eight rats per box with food and water continuously available. Three days after arrival in the laboratory, rats were handled each day for $4 \mathrm{~d}$. The experimental procedures were approved by the Animal Ethics Committee at the University of New South Wales and conducted in accordance with the National Institutes of Health Guidelines for the Care and Use of Laboratory Animals (publication DHHS NIH 86-23). All experiments occurred between 7:00 a.m. and 10:00 p.m.

\section{Drugs}

The $\mathrm{GABA}_{\mathrm{A}}$ receptor agonist muscimol (Sigma) was dissolved in $0.9 \%(\mathrm{w} / \mathrm{v})$ nonpyrogenic saline to obtain a final concentration of $6.25 \mathrm{ng} / \mu \mathrm{L}$. Nonpyrogenic saline was used to control for any effect of the infusion procedures per se. The dose of muscimol was selected on the basis of a pilot study showing that this dose did not impair the expression of fear responses (i.e., freezing).

\section{Surgery and microinjections}

Rats received intraperitoneally (i.p.) injections of $1.3 \mathrm{~mL} / \mathrm{kg}$ of the anesthetic ketamine (Ketapex, Apex Laboratories) at a concentration of $100 \mathrm{mg} / \mathrm{mL}$ and of $0.3 \mathrm{~mL} / \mathrm{kg}$ of the muscle relaxant xylazine (Rompun; Bayer) at a concentration of $20 \mathrm{mg} / \mathrm{mL}$. Anaesthetized rats were then mounted on a stereotaxic apparatus (Kopf Instruments), and 26-gauge double-guide cannulas (Plastics One) were implanted through holes drilled in both hemispheres of the skull. The tips of the guide cannulas were aimed bilaterally at either the PL (AP, +3.1; ML, \pm 0.6 ; DV, -2.5 ) or the IL (AP, +2.5; ML, 
\pm 0.6 ; DV, -3.9 ). The guide cannulas were maintained in position with dental cement, and dummy cannulas were kept in each guide at all times except during microinjections. Immediately after the surgical procedure, rats were injected i.p. with a prophylactic $(0.3 \mathrm{~mL})$ dose of $300 \mathrm{mg} / \mathrm{kg}$ solution of procaine penicillin. Rats were allowed $4 \mathrm{~d}$ to recover from surgery, during which time they were handled and weighed daily.

Muscimol $(6.25 \mathrm{ng} / \mu \mathrm{L})$ and vehicle were infused bilaterally in the PL or the IL by inserting a 33-gauge double-internal cannula into the double-guide cannula. The double-internal cannula was connected to a $25-\mu \mathrm{L}$ glass syringe attached to an infusion pump (Harvard Apparatus) and projected an additional $1 \mathrm{~mm}$ ventral to the tip of the guide cannula. A total volume of $0.2 \mu \mathrm{L}$ (each side) was delivered at a rate of $0.1 \mu \mathrm{L} / \mathrm{min}$. The double-internal cannula remained in place for a further 1 min after the infusions and was then removed. On the day before infusions, the dummy cannula was removed and the infusion pump was turned on for $3 \mathrm{~min}$ in order to familiarize the rats with the procedure and thereby minimize any stress produced by this procedure when infusions occurred. All infusions occurred in a separate room from the colony room and the experimental room.

\section{Apparatus}

Four chambers, each measuring 30 -cm height $\times 30$-cm length $\times$ $25-\mathrm{cm}$ width were used for preexposure, fear conditioning, extinction training, and testing. The front and rear walls of these chambers, as well as the hinged lid, were constructed of Perspex, and the end walls were made of stainless steel. The floor in each chamber consisted of stainless steel rods, $6 \mathrm{~mm}$ in diameter, spaced $10 \mathrm{~mm}$ apart (center to center). Each chamber was enclosed in a sound- and light-attenuated shell. The inside walls of the shells were painted black. Illumination for each chamber was provided by a white fluorescent tube mounted on the back of the wall of each shell ( $\sim 57$ lux measured at the center of the chamber). A fan was mounted on the side wall of each shell to recycle air. The US was a 1-sec, 0.8-mA unscrambled AC $50-\mathrm{Hz}$ footshock from a constant-current generator that was delivered to the floor of each chamber. The current available to each floor could be adjusted using an in-line milliampere meter. The floor of each chamber was $3 \mathrm{~cm}$ above a tray of paper pellet bedding (Fibrecycle) that was changed between rats. After removal of a rat, the floor of each chamber was cleaned with a solution of acetic acid (1\%) to eliminate any residue and provide a distinctive odor. A camera mounted on the back wall of each shell was used to record the behavior of each rat. Each camera was connected to a monitor and a DVD recorder located in another room of the laboratory. This room contained the computer that controlled stimulus presentations via appropriate software (LabView, National Instruments).

\section{Behavioral procedures}

Experiment 1: Inactivation of the PL spares learning and relearning extinction

To minimize any deficits in conditioned fear response due to the surgical procedure, all experiments included a preexposure phase. This consisted in exposing rats to the training chambers for $8 \mathrm{~min}$ on day 1 . Such exposure has been shown to facilitate the subsequent acquisition of fear responses (Fanselow 1990; Kiernan and Westbrook 1993; Wiltgen et al. 2001). Four hours after preexposure, rats were placed in the chambers and shocked $(0.8 \mathrm{~mA} \times$ $1 \mathrm{sec}) 1 \mathrm{~min}$ later. They remained in the chambers for a further $2 \mathrm{~min}$ and were then returned to their home cages. On day 2, rats in groups Re-extinction received an extinction session that consisted of a 20-min exposure to the chambers in the absence of footshock. Rats in groups Extinction did not receive an extinction session but were handled. On day 3 , all rats received a second conditioning episode identical to the one described on day 1 . On day 4, rats in groups Extinction-Muscimol and Re-extinctionMuscimol received an infusion of muscimol $(6.25 \mathrm{ng} / \mu \mathrm{L} ; 0.2 \mu \mathrm{L}$ per side) into the PL, whereas those in groups Extinction-Vehicle and Re-extinction-Vehicle received an infusion of saline. Fortyfive minutes after infusion, all rats received an extinction session identical to that on day 2. Six hours after this extinction session, rats that had been infused with muscimol now received an infusion of saline (groups Extinction-Muscimol and Re-extinctionMuscimol), and rats that had been infused with saline now received an infusion of muscimol (groups Extinction-Vehicle and Re-extinction-Vehicle). These counterbalanced infusions were used to control for any effects of muscimol per se on responding across the subsequent test. On day 5, all rats were tested for fear responses in the chambers across a 10-min extinction session.

\section{Experiment 2: Inactivation of the IL impairs learning and relearning extinction}

The procedure in this experiment was identical to that in experiment 1, except that muscimol was infused in the PL. On day 1, all rats were preexposed and received a shocked exposure to the chambers in the manner described. On day 2, rats in groups Reextinction received an extinction session that was the same as that described. On this day, rats in groups Extinction did not receive an extinction session but were handled. On day 3 , all rats received a conditioning episode identical to that on day 1 . On day 4 , rats in groups Extinction-Muscimol and Re-extinction-Muscimol were infused with muscimol ( $6.25 \mathrm{ng} / \mu \mathrm{L} ; 0.2 \mu \mathrm{L}$ per side) into the IL, whereas those in groups Extinction-Vehicle and Re-extinctionVehicle were infused with saline. Forty-five minutes after infusion, all rats received an extinction session identical to that on day 2 . Counterbalanced infusions were given $6 \mathrm{~h}$ later in the manner described. On day 5 , all rats were tested in the manner described.

\section{Experiment 3: Inactivation of the IL impairs the consolidation of re-extinction}

In this experiment, infusion of muscimol was given in the IL after the second extinction session. Following preexposure, on day 1, rats were shocked in the chambers in the manner described. On day 2 , all rats received an extinction session that was the same as that described. On day 3 , all rats were given a conditioning episode identical to that on day 1 . On day 4 , rats in group Re-extinctionMuscimol received an infusion of muscimol in the IL, whereas those in groups Re-extinction-Vehicle and Control Re-extinction received an infusion of saline. Forty-five minutes after infusion, rats in groups Re-extinction received an extinction session identical to that on day 2. Counterbalanced infusions were given $6 \mathrm{~h}$ later in the manner described. On day 5 , all rats were tested in the manner described.

\section{Experiment 4: Inactivation of the IL impairs retrieval of learned inhibition}

This experiment manipulated neuronal activity in the IL across testing of an extinguished context. Following preexposure on day 1 , all rats received a shocked exposure to the chambers in the manner described. Rats were handled on day 2 and received on day 3 a second conditioning episode identical to that on day 1 . On day 4, rats in groups Extinction received an extinction session identical to that described. Rats in group Control Extinction did not receive an extinction session but were handled. On day 5, rats in group Extinction-Muscimol were infused with muscimol in the IL, whereas rats in groups Extinction-Vehicle were infused with saline. Half of the rats in group Control Extinction received an infusion of muscimol, whereas the other half received saline. Forty-five minutes after infusion, all rats were tested in the chambers in the manner described.

\section{Histology}

Subsequent to behavioral testing, subjects implanted with cannulas received a lethal dose of sodium pentobarbital and their brains were removed and frozen. Unfixed brains were sectioned coronally at $40 \mu \mathrm{m}$ through the PL or the IL. Every third section was collected on a slide, and the sections were stained with cresyl violet. The approximate location of injection cannulas tips was determined under a microscope by a trained observer who was unaware of the subjects' group designations by use of the boundaries defined by the Paxinos and Watson atlas (Paxinos and Watson 2007). Subjects with inaccurate double-guide cannula placements or with extensive damage to the PL or IL were 
excluded from the statistical analysis. Importantly, the behavior exhibited by these subjects did not follow any particular trend. Thus, the data are not discussed here.

\section{Scoring and statistics}

Freezing was defined as the absence of all movements, except those related to breathing (Blanchard and Blanchard 1969). The behavior of each rat was recorded on videotape, and freezing was rated with a time-sampling procedure in which each rat was observed every $2 \mathrm{sec}$ and scored as either freezing or moving. A percentage score was calculated for the proportion of the total observation that each rat spent freezing. Freezing was rated by two observers, one of whom was unaware of the subject's group designation. There was a high degree of agreement between the two observers: The Pearson product moment correlation between their rating was $>0.95$. The data were analyzed in each experiment by a set of planned nonorthogonal contrasts that controlled the error rate using the Bonferroni inequality procedure. Significance was set at the 0.05 level. The behavior of each experimental group was represented as percent levels of freezing per minute except for the retention test. This was to ease the readability of the results. In all experiments, there was no significant interaction between levels of freezing and the number of minutes spent in the chambers $(F \mathrm{~s}<3.055)$.

\section{References}

Blair HT, Schafe GE, Bauer EP, Rodrigues SM, LeDoux JE. 2001. Synaptic plasticity in the lateral amygdala: A cellular hypothesis of fear conditioning. Learn Mem 8: 229-242.

Blanchard RJ, Blanchard DC. 1969. Crouching as an index of fear. J Comp Physiol Psychol 67: 370-375.

Bouton ME, Westbrook RF, Corcoran KA, Maren S. 2006. Contextual and temporal modulation of extinction: Behavioral and biological mechanisms. Biol Psychiatry 60: 352-360.

Bremner JD, Staib LH, Kaloupek D, Southwick SM, Soufer R, Charney DS. 1999. Neural correlates of exposure to traumatic pictures and sound in Vietnam combat veterans with and without posttraumatic stress disorder: A positron emission tomography study. Biol Psychiatry 45: 806-816.

Burgos-Robles A, Vidal-Gonzalez I, Santini E, Quirk GJ. 2007. Consolidation of fear extinction requires NMDA receptor-dependent bursting in the ventromedial prefrontal cortex. Neuron 53: 871-880.

Corcoran KA, Quirk GJ. 2007. Activity in prelimbic cortex is necessary for the expression of learned, but not innate, fears. J Neurosci 27: 840844.

Fanselow MS. 1990. Factors governing one trial contextual fear conditioning. Anim Learn Behav 18: 264-270.

Hart G, Harris JA, Westbrook RF. 2009. Systemic or intra-amygdala injection of a benzodiazepine (midazolam) impairs extinction but spares reextinction of conditioned fear responses. Learn Mem 16: 53-61.

Herry C, Garcia R. 2002. Prefrontal cortex long-term potentiation, but not long-term depression, is associated with the maintenance of extinction of learned fear in mice. $J$ Neurosci 22: 577-583.

Herry C, Trifilieff P, Micheau J, Luthi A, Mons N. 2006. Extinction of auditory fear conditioning requires MAPK/ERK activation in the basolateral amygdala. Eur I Neurosci 24: 261-269.

Herry C, Ciocchi S, Senn V, Demmou L, Muller C, Luthi A. 2008. Switching on and off fear by distinct neuronal circuits. Nature 454: 600-606.

Hugues S, Chessel A, Lena I, Marsault R, Garcia R. 2006. Prefrontal infusion of PD098059 immediately after fear extinction training blocks extinction-associated prefrontal synaptic plasticity and decreases prefrontal ERK2 phosphorylation. Synapse 60: 280-287.

Kiernan MJ, Westbrook RF. 1993. Effects of exposure to a to-be-shocked environment upon the rat's freezing response: Evidence for facilitation, latent inhibition, and perceptual learning. Q J Exp Psychol B 46: 271288.

Kim JH, Richardson R. 2008. The effect of temporary amygdala inactivation on extinction and re-extinction of fear in the developing rat: Unlearning as a potential mechanism for extinction early in development. J Neurosci 28: 1282-1290.
Kim J, Lee S, Park H, Song B, Hong I, Geum D, Shin K, Choi S. 2007. Blockade of amygdala metabotropic glutamate receptor subtype 1 impairs fear extinction. Biochem Biophys Res Commun 355: 188-193.

Laurent V, Westbrook RF. 2008. Distinct contributions of the basolateral amygdala and the medial prefrontal cortex to learning and relearning extinction of context conditioned fear. Learn Mem 15: 657-666.

Laurent V, Marchand AR, Westbrook RF. 2008. The basolateral amygdala is necessary for learning but not relearning extinction of context conditioned fear. Learn Mem 15: 304-314.

Leung HT, Westbrook RF. 2008. Spontaneous recovery of extinguished fear responses deepens their extinction: A role for error-correction mechanisms. J Exp Psychol Anim Behav Process 34: 461-474.

Likhtik E, Popa D, Apergis-Schoute J, Fidacaro GA, Pare D. 2008. Amygdala intercalated neurons are required for expression of fear extinction. Nature 454: 642-645.

Lin CH, Yeh SH, Lu HY, Gean PW. 2003. The similarities and diversities of signal pathways leading to consolidation of conditioning and consolidation of extinction of fear memory. J Neurosci 23: 8310-8317.

McDonald AJ. 1998. Cortical pathways to the mammalian amygdala. Prog Neurobiol 55: 257-332.

Milad MR, Quirk GJ. 2002. Neurons in medial prefrontal cortex signal memory for fear extinction. Nature 420: 70-74.

Myers KM, Davis M. 2007. Mechanisms of fear extinction. Mol Psychiatry 12: $120-150$.

Pare D, Smith Y. 1993. The intercalated cell masses project to the central and medial nuclei of the amygdala in cats. Neuroscience 57: 1077-1090.

Paxinos G, Watson C. 2007. The rat brain in stereotaxic coordinates. Academic, Sydney, Australia.

Quirk GJ, Mueller D. 2008. Neural mechanisms of extinction learning and retrieval. Neuropsychopharmacology 33: 56-72.

Quirk GJ, Likhtik E, Pelletier JG, Pare D. 2003. Stimulation of medial prefrontal cortex decreases the responsiveness of central amygdala output neurons. J Neurosci 23: 8800-8807.

Rescorla RA. 2001. Retraining of extinguished Pavlovian stimuli. J Exp Psychol Anim Behav Process 27: 115-124.

Rescorla RA, Wagner AR. 1972. A theory of Pavlovian conditioning: Variations in the effectiveness of reinforcement and nonreinforcement. Appleton Century Crofts, New York.

Royer S, Pare D. 2002. Bidirectional synaptic plasticity in intercalated amygdala neurons and the extinction of conditioned fear responses. Neuroscience 115: 455-462.

Royer S, Martina M, Pare D. 1999. An inhibitory interface gates impulse traffic between the input and output stations of the amygdala. J Neurosci 19: 10575-10583.

Sah P, Faber ES, Lopez De Armentia M, Power J. 2003. The amygdaloid complex: Anatomy and physiology. Physiol Rev 83: 803-834.

Santini E, Ge H, Ren K, Pena de Ortiz S, Quirk GJ. 2004. Consolidation of fear extinction requires protein synthesis in the medial prefrontal cortex. J Neurosci 24: 5704-5710.

Santini E, Quirk GJ, Porter JT. 2008. Fear conditioning and extinction differentially modify the intrinsic excitability of infralimbic neurons. $J$ Neurosci 28: 4028-4036.

Shin LM, Whalen PJ, Pitman RK, Bush G, Macklin ML, Lasko NB, Orr SP McInerney SC, Rauch SL. 2001. An fMRI study of anterior cingulate function in posttraumatic stress disorder. Biol Psychiatry 50: 932-942.

Sierra-Mercado D Jr, Corcoran KA, Lebron-Milad K, Quirk GJ. 2006. Inactivation of the ventromedial prefrontal cortex reduces expression of conditioned fear and impairs subsequent recall of extinction. Eur $J$ Neurosci 24: 1751-1758.

Sotres-Bayon F, Bush DE, LeDoux JE. 2007. Acquisition of fear extinction requires activation of NR2B-containing NMDA receptors in the lateral amygdala. Neuropsychopharmacology 32: 1929-1940.

Sotres-Bayon F, Diaz-Mataix L, Bush DE, LeDoux JE. 2009. Dissociable roles for the ventromedial prefrontal cortex and amygdala in fear extinction: NR2B contribution. Cereb Cortex 19: 474-482.

Vidal-Gonzalez I, Vidal-Gonzalez B, Rauch SL, Quirk GJ. 2006. Microstimulation reveals opposing influences of prelimbic and infralimbic cortex on the expression of conditioned fear. Learn Mem 13: 728-733.

Wiltgen BJ, Sanders MJ, Behne NS, Fanselow MS. 2001. Sex differences, context preexposure, and the immediate shock deficit in Pavlovian context conditioning with mice. Behav Neurosci 115: 26-32.

Received May 3, 2009; accepted in revised form July 13, 2009. 


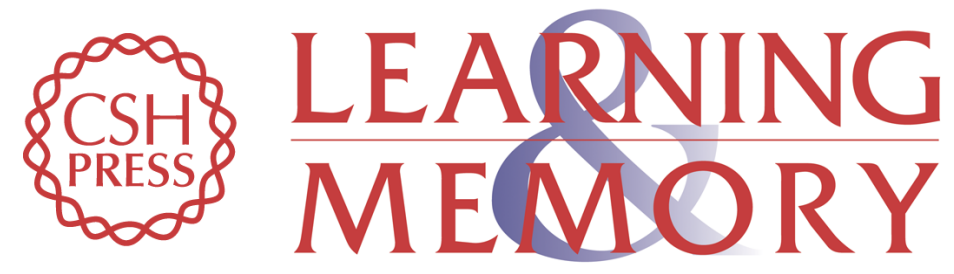

\section{Inactivation of the infralimbic but not the prelimbic cortex impairs consolidation and retrieval of fear extinction}

Vincent Laurent and R. Frederick Westbrook

Learn. Mem. 2009, 16:

Access the most recent version at doi:10.1101//m.1474609

References This article cites 38 articles, 13 of which can be accessed free at:

http://learnmem.cshlp.org/content/16/9/520.full.html\#ref-list-1

License

Email Alerting Receive free email alerts when new articles cite this article - sign up in the box at the Service top right corner of the article or click here. 